\title{
Modified Han algorithm for inconsistent linear inequalities
}

\section{DOINA CARP, CONSTANTIN POPA and CRISTINA SERBAN}

\section{ABSTRACT.}

In this paper we present a modified version of S. P. Han iterative method for solving inconsistent systems of linear inequalities. Our method uses an iterative Kaczmarz-type solver to approximate the minimal norm least squares solution of the problems involved in each iteration of Han's algorithm. We prove some convergence properties for the sequence of approximations generated in this way and present numerical experiments and comparisons with Han's and other direct solver based methods for inconsistent linear inequalities.

Acknowledgements. For Cristina Serban, this work was supported by the project Sustainable performance in doctoral and post-doctoral research-PERFORM co-funded from the European Social Fund through the Development of Human Resources Operational Programme 20072013, Contract No.POSDRU/159/1.5/S/138963

\section{REFERENCES}

[1] Bennett, K. and Mangasarian, O., Robust linear programming discrimination of two linearly inseparable sets, Optimization Methods and Software, 1 (1992), 23-34

[2] Bramley, R. and Winnicka, B., Solving linear inequalities in a least squares sense, SIAM J. Sci. Comp., 17 (1996), No. 1, 275-286

[3] Bramley, R. and Winnicka, B., Solving linear inequalities in a least squares sense, Technical Report TR 396 , January 1994, School of Informatics and Computing, Indiana University - Bloomington, USA

[4] Carp, D., Popa, C. and Serban, C., Iterative solution of inconsistent systems of linear inequalities, submitted for publication in Proceedings on Applied Mathematics and Mechanics (PAMM)

[5] Censor, Y. and Stavros, A. Z., Parallel optimization: theory, algorithms and applications, Numer. Math. and Sci. Comp. Series, Oxford University Press, New York, 1997

[6] Han, S. -P., Least squares solution of linear inequalities, Tech. Rep. TR-2141, Mathematics Research Center, University of Wisconsin - Madison, 1980

[7] Köstler, H., Popa, C., Preclik, T. and Rüede, U., On Kaczmarz's projection iteration as a direct solver for linear least squares problems, Linear Algebra and its Applications 436 (2012), No. 2, 389-404

[8] Popa, C., Extensions of block-projections methods with relaxation parameters to inconsistent and rank-defficient least-squares problems; B I T Numerical Analysis, 38 (1998), No. 1, 151-176

[9] Popa, C., Projection algorithms - classical results and developments. Applications to image reconstruction. Lambert Academic Publishing - AV Akademikerverlag GmbH \& Co. KG, Saarbrücken, Germany, (2012)

[10] University of California-Irvine Repository of Machine Learning Databases and Domain Theories, $\mathrm{ftp}$ / / ftp.ics.uci.edu/pub/machine-learning-databases/

[11] Yang, K., New iterative methods for linear inequalities, Tech. report 90-6, February 1990, Department of Industrial and Operations Engineering, University of Michigan, USA

CONSTANTA MARITIME UNIVERSITY

FACULTY OF NAVIGATION

Mircea Cel BATRAN 104, CONSTANTA 900663, Romania

E-mail address: doina. carp@gmail. com

Received: 21.06.2013; In revised form: 25.03.2014; Accepted: 23.04.2014

2010 Mathematics Subject Classification. 65F10, 65F20.

Key words and phrases. Inconsistent linear inequalities, Han algorithm, Kaczmarz Extended algorithm, convergence.

Corresponding author: Constantin Popa; cpopa1956@gmail.com 
OVIDIUS UNIVERSITY OF CONSTANTA

FACULTY OF MATHEMATICS AND INFORMATICS

MAMAIA 124, CONSTANTA 900527, ROMANIA

E-mail address: cpopa1956@gmail.com

OVIDIUS UNIVERSITY OF CONSTANTA

FACULTY OF CIVIL ENGINEERING

UNIRII 22B, CONSTANTA 900524, ROMANIA

E-mail address: cgherghina@gmail.com 